\title{
Evan Thompson
}

\section{Précis of Mind in Life: Biology, Phenomenology, and the Sciences of Mind}

\section{Introduction}

The theme of this book is the deep continuity of life and mind. Where there is life there is mind, and mind in its most articulated forms belongs to life. Life and mind share a core set of formal or organizational properties, and the formal or organizational properties distinctive of mind are an enriched version of those fundamental to life.

I take a twofold approach to these ideas in Mind in Life. On the one hand, I try to show that to be a living organism is physically to realize or instantiate a certain kind of self-organization - one that entails an autonomous and normative and cognitive mode of being in relation to the world. On the other hand, I try to show that certain features of the human mind, especially various structural features of conscious experience, are constituted by self-organizing processes of the human body engaged with its environment. In this twofold way, I hope to provide new resources for addressing the explanatory gap between consciousness and nature.

The book's subtitle indicates the principal resources from which I draw - biology, phenomenological philosophy stemming from Edmund Husserl and Maurice Merleau-Ponty, and the cognitive and brain sciences.

Any attempt to synthesize material from these disciplines faces two immediate challenges. On the one hand, traditional phenomenology would reject my proposal that advances in biology and the sciences of mind and brain can properly address issues about the teleology of life 
and the intentionality of consciousness. On the other hand, contemporary biology, neuroscience, and psychology would see phenomenology as irrelevant to their explanatory efforts and concerns. Hence another goal of my book is to show that science and phenomenology need each other and can work together productively to understand mind and life. I try to make good on this proposal in Part Three through detailed analyses of body awareness (Chapter Nine), perception and mental imagery (Chapter Ten), time consciousness (Chapter Eleven), emotion (Chapter Twelve), and empathy and intersubjectivity (Chapter Thirteen).

Instead of trying to summarize these analyses and their supporting arguments, I will present in this Précis some of the main ideas of Mind in Life in relation to the book's overarching aim.

\section{The Guiding Idea}

Mind in Life seeks to make headway on the contemporary problem of the explanatory gap between consciousness and nature. I take my inspiration from Maurice Merleau-Ponty's first and revolutionary work, The Structure of Behavior (1942/1963). As he states at the outset of this work, the goal is 'to understand the relations of consciousness and nature: organic, psychological, or even social' (ibid., p. 3). Like Merleau-Ponty, who drew extensively from the scientific knowledge of his time while reinterpreting it from a critical perspective informed by phenomenology, I try to synthesize contemporary systems biology, cognitive science, and phenomenology into a unified treatment of life and mind. In this way, my work can be read as an attempt to update and advance Merleau-Ponty's original approach to understanding consciousness and nature.

Merleau-Ponty's strategy is to introduce a third term, something that does not fit the consciousness/nature dichotomy in modern (Cartesian) philosophy, something that forces us to revise how we think about matter, life, and mind. This third term is behaviour (comportement). A thorough investigation of behaviour at multiple levels of complexity reveals that even inorganic material processes, as well as living and mental ones, are structured unities rather than multiplicities of events external to each other and bound together by efficient causal relations. Specifically, behaviour is always a structured and dynamic whole, in which organism and milieu participate not as externally related stimulus and reaction, but as internally related situation and response. 
Merleau-Ponty differentiates various types or levels of behaviour in terms of the form or structure that they realize. By 'form' or 'structure' he means a dynamic whole that cannot be dislocated from its components but cannot be reduced to them either. He uses this notion to characterize what he calls the three orders of matter, life, and mind. These orders 'participate unequally in the nature of form', 'represent different degrees of integration', and 'constitute a hierarchy in which individuality is progressively achieved' (Merleau-Ponty, 1942/1963, p. 133). Using this framework, Merleau-Ponty eventually arrives at an explication of human consciousness as a form or structure of behaviour - a dynamic mode of comportment - that achieves a certain kind of individuality in relation to its milieu. ${ }^{1}$

He begins with the notion of form or structure in physics. A physical form, like a soap bubble or a convection roll, is a structural stability established in relation to given external conditions and thus stands out as a qualitative discontinuity in the material substrate (MerleauPonty, 1942/1963, p. 145). A physical form achieves individuality in the sense of being an invariant topological pattern in a changing material substrate (like a tornado and its air and water molecules).

The living order is characterized by the emergence of a new kind of structure in the physical order. The simplest living forms are metabolic structures that produce their own material constituents and thereby also realize themselves as self-producing individuals. A living cell dynamically produces itself through the continual material turnover of its constituents while regulating the flow of matter and energy around it and through it. The material and energetic demands of this entire process orient the cell of necessity toward the environment, which the cell transforms through its activity into a proper milieu or niche. Thus, whereas physical structures can be expressed by a law, living structures have to be comprehended in relation to norms: '[E]ach organism, in the presence of a given milieu, has its optimal conditions of activity and its proper manner of realizing equilibrium' (ibid., p. 148). A living cell or organism 'modifies its milieu according to the internal norms of its activity' (ibid., p. 154).

Merleau-Ponty's third order is the human order. Its most typical structures and forms of behaviour are symbolic. ${ }^{2}$ Symbolic behaviour is directed not toward things or objects as such but toward 'use-

[1] Hans Jonas (1966) pursues a similar strategy in his book The Phenomenon of Life. I relate Jonas's work to the theory of autopoiesis in systems biology in Chapter Six.

[2] Merleau-Ponty takes human symbolic behaviour as paradigmatic of mind, hence his alignment of matter, life, and mind with the physical, vital, and human orders. He also classifies animal behaviour according to the degree to which its structure (and hence the 
objects' - things endowed with culturally constituted meanings. Thus symbolic behaviour implies the enactment of a whole new kind of milieu, one whose structure is 'perceived situation-work' (ibid., p. 162). By 'perceived situation' Merleau-Ponty means perception of the action of other subjects, upon which is founded the perception of things as cultural use-objects. By 'work' he means activities (ensembles of intentional actions) that transform physical and living nature and thereby modify the milieu or produce a new one. By altering the present milieu, work in effect negates it in favour of a new one. The correlative form of perception required for work is perception that presents its object not as something simply there now (something present and actual), but as something of use that can change other things (something oriented in relation to the future and possibilities).

The burden of Merleau-Ponty's argument in The Structure of Behavior is thus to show that the notion of form or structure can both integrate the orders of matter, life, and mind and account for the originality of each order. On the one hand, nature is not pure exteriority, but rather in the case of life has its own interiority and thus resembles mind. On the other hand, mind is not pure interiority, but rather a form or structure of engagement with the world and thus resembles life.

But what about consciousness? Merleau-Ponty rejects the idea that conscious experiences are interior states of the mind or brain that stand as causal or epiphenomenal intermediaries between sensory inputs and motor outputs. Consciousness is rather a form or structure of comportment, a perceptual and motor attunement of the whole animal to its world. In our human case, this attunement is primarily to an environment of meaningful symbols and the intentional actions of others. Merleau-Ponty uses the following example to illustrate these ideas:

For the player in action the football field is not an 'object,' that is, the ideal term which can give rise to an indefinite multiplicity of perspectival views and remain equivalent under its apparent transformations. It is pervaded with lines of force (the 'yard lines'; those which demarcate the 'penalty area') and articulated in sectors (for example, the 'openings' between the adversaries) which call for a certain mode of action and which initiate and guide the action as if the player were unaware of it. The field itself is not given to him, but present as the immanent term of his practical intentions; the player becomes one with

organism) is submerged in or emergent from the organism's concrete situation (MerleauPonty, 1942/1963, p. 103). The more emergent the structure of behaviour is with respect to the milieu, the more effectively the organism can dominate situations and learn. The more effectively the organism can withdraw from and exercise control over its immersion in the milieu, the more it triumphs over immediacy and achieves individuality (ibid., pp. 104-24). 
it and feels the direction of the 'goal,' for example, just as immediately as the vertical and the horizontal planes of his own body. It would not be sufficient to say that consciousness inhabits this milieu. At this moment consciousness is nothing other than the dialectic of milieu and action. Each maneuver undertaken by the player modifies the character of the field and establishes in it new lines of force in which the action in turn unfolds and is accomplished, again altering the phenomenal field. (Merleau-Ponty, 1942/1963, pp. 168-9, emphasis added)

In Mind in Life I try to develop this way of looking at life, mind, and consciousness for contemporary philosophy and science. First, by combining the theory of autopoiesis (Maturana and Varela, 1980; 1987) with Hans Jonas's (1966) phenomenological analysis of life, I argue that life or living being instantiates a kind of interiority that escapes the objectivist picture of nature (Part Two). Second, by combining phenomenological analyses of intentional experience with embodied cognitive science, I argue that subjectivity instantiates a kind of exteriority that escapes the internalist picture of consciousness (Part Three). In this way, I aim to reduce the conceptual and epistemological distance between life and consciousness and thereby alter the nature and significance of the explanatory gap.

\section{A Pressing Objection}

In the context of today's discussions of consciousness, especially in the philosophy of mind, an objection to this kind of embodied approach will immediately spring to mind. Take Merleau-Ponty's example of the soccer player. Is it not possible for the same sort of dynamic sensorimotor engagement with the environment to take place in the absence of consciousness? So how could forms or structures of comportment be constitutive of consciousness?

In its starkest form, this kind of objection can be stated as the notorious zombie thought experiment. A zombie is supposed to be a system that is physically identical to a conscious being (say, you) but that lacks conscious experience altogether. In other words, it is supposed to have exactly the same physical structure, functional mechanisms and behaviour as a conscious human being, minus the consciousness. If such a being is logically or conceptually possible, if it is genuinely conceivable without contradiction or some other kind of incoherence, then (so the argument goes) no account of consciousness in terms of physical structure and function - or even in terms of Merleau-Ponty's phenomenological conception of comportment - can be correct.

The zombie thought experiment provides an extreme case of the radical conceptual divorce between consciousness and life. Your 
hypothetical zombie twin is physically and biologically identical to you; it is a complete duplicate of the biological organism that you are. It is therefore alive exactly as you are, with regard to every structural, functional, and behavioural detail. Nevertheless, it does not feel alive in the slightest; it is not sentient.

Although philosophers who advance the zombie argument do not seem worried by this thought, it strikes me as hardly comprehensible. We are asked to imagine a living being, a human organism, whose bodily life is identical with respect to its physical structure and function to that of a conscious human being, but that has no bodily sentience, no subjective experience of its bodily existence and environment. In phenomenological language, we are asked to imagine a physical living body (Körper) that is not a lived body (Leib). It is hardly clear that this scenario is conceivable or imaginable strictly as described. The scenario requires that a physical counterpart (a molecule-for-molecule duplicate) of a given conscious subject's actual-world body have a bodily life indistinguishable from that of the conscious subject in every respect except for having no subjective experience whatsoever of its own body.

Yet many of the perceptual and motor abilities of one's physical living body (the body as Körper) evidently depend on that body's being a subjectively lived body (a Leib). Without proprioceptive and kinaesthetic experience, for example, many kinds of normal perception and motor action cannot happen. The zombie scenario requires the assumption that bodily experience is not necessary for or in any way constitutive of the relevant behaviour, that exactly the same behaviour is possible without bodily sentience. This assumption is quite strong and needs to be argued for independently. There is little reason to believe it. Although one can make a conceptual distinction between bodily experience from the inside and bodily functioning from the outside, it hardly follows that the latter could exist without the former.

In Mind in Life I relate this line of thought to phenomenological analyses of perception (pp. 231-3). One of the central themes of Husserl's analyses of perception is that every visual or tactile perception is accompanied by, and functionally linked to, the sensing of one's bodily movements (hand movements, eye movements, head movements, whole-body movements, and so on - Husserl, 1997). Every aspect or profile of an object given to tactile or visual perception is not simply correlated to a kinaesthetic experience of one's body but is functionally tied to that experience. When one touches the computer keys, the keys are given in conjunction with a sensing of one's finger movements; when one watches a bird in flight, the bird is given 
in conjunction with a sensing of one's head and eye movements. Husserl argues at length that perceptual continuity — the continuity of the object through a changing manifold of appearances - depends on this linkage of kinaesthesis and perception. As he states, it is through one's movement and bodily self-experience in movement that an object presents itself as a unified series of appearances. In other words, bodily self-experience in the form of kinaesthesis is a constitutive condition of ordinary perception.

Behind this analysis is the idea that in order to perceive an object from a certain perspective - to take its appearance or profile from that perspective as an appearance of an objective thing in space - one needs to be aware, tacitly or pre-reflectively, of other co-existing but absent profiles of the object. These absent profiles stand in a certain relation to the present one: they can become present if one carries out certain movements. In other words, they are correlated to one's kinaesthetic system of possible bodily movements and positions. If one moves this way, then that aspect of the object becomes visible; if one moves that way, then this aspect becomes visible. In Husserl's terminology, perception is 'kinaesthetically motivated'.

The result is that pre-reflective bodily experience, the tacit experience of one's body, is constitutive of perception. How, then, can we make sense of the idea of a completely unconscious being, a being with no experience whatsoever of its own body, whose (functionally defined) perceptual abilities are exactly those of its (physically identical) conscious counterpart? For this scenario to make sense it must be conceivable that a being having normal human perceptual abilities could have no kinaesthetic experience of its body and no pre-reflective experience of itself as an embodied agent. But if the phenomenological analysis is right, then bodily experience is constitutive of the perceptual function of individuating continuous objects in space through a manifold of sensory appearances. So any being that was capable of the same perceptual function would need to have an experience of its own body and hence could not be a zombie.

Although this line of thought should undermine confidence in the imaginability of the zombie scenario, it does not demonstrate that the scenario is inconceivable in the strict sense of being logically contradictory. My aim, however, is not to refute the belief in the logical possibility of zombies, as it were, head-on. One does not need to demonstrate the logical impossibility of zombies by deriving a formal contradiction from the supposition to call into question this supposition's philosophical value (pace Chalmers, 1996, p. 96). One need only reveal the problematic assumptions on which it rests - that exactly the same 
behaviour can happen in the presence and absence of sentience, and that sentience is a strictly internal and phenomenal occurrence, whereas behaviour is entirely a matter of external structure and function. Given these problematic assumptions, philosophers should not be allowed to get away with simply asserting that the zombie scenario seems conceivable to them. They must describe the scenario in sufficient detail so that it is intelligible given the apparent inseparability of a conscious subject's physical living body (its Körper) and its lived body (its Leib).

These considerations indicate that the zombie argument carries no weight against the embodied approach that views certain structures of comportment as constitutive of certain kinds of consciousness. More generally, these considerations indicate that instead of starting from the concepts of mind and body in standard formulations of the explanatory gap or hard problem of consciousness we need to take our start from the lived body. For these reasons, in Mind in Life I reformulate the problem of the explanatory gap by taking life and the body as our starting point.

\section{The Body-Body Problem}

Phenomenologists distinguish between two ways the body can be disclosed to our experience - as a material thing (Körper) and as a living subject of experience or lived body (Leib). ${ }^{3}$ In addition to this basic distinction, we can distinguish between the structural morphology of the physical body and its living and lived dynamics. The morphology comprises the bodily structures of limbs, organs, regulatory systems, brain structures, and so on, whereas the dynamics comprises the lived flow of life, that is, the flow of intentional movement and lived sensations (interoceptive, exteroceptive, and proprioceptive). There does not seem to be any explanatory gap between seeing the body as a material object and seeing it in its structural morphology as a living body. But there does seem to be a gap or discontinuity between seeing the body as a living body and seeing it as a lived body, as a locus of feeling and intentional activity - in short as sentient. The body-body problem is to understand the relation between the body as a living being and the body as a lived body or bodily subject of experience.

Two points are important here. First, the explanatory gap is no longer between two radically different ontologies (mental and physical), but between two types within one typology of embodiment. Second,

[3] Note that this distinction is not equivalent to the distinction between the third-person and first-person perspectives, for others are disclosed to us as lived bodies from the third-person and second-person perspectives; see Chapter Thirteen. 
the gap is no longer absolute because in order to formulate it we need to make common reference to life or living being.

These differences between the body-body problem and the Cartesian hard problem are philosophically non-trivial. In the hard problem the explanatory gap is absolute because there is no common factor between the mental and the physical (and there can be none given how they are defined). Hence the main options are either to accept the gap as a brute ontological fact (dualism), to close the gap by reduction (materialism or idealism), or to bridge the gap by introducing some third and speculative 'extra ingredient' (for which there is no scientific evidence or motivation). These options make little sense for the body-body problem. The lived body is the living body; it is a dynamic condition of the living body. We could say that our lived body is a performance of our living body, something our body enacts in living. The philosophical task is to show how there can be an account of the lived body that integrates biology and phenomenology, and so goes 'beyond the gap'. The scientific task is to understand how the organizational and dynamic processes of a living body can become constitutive of a subjective point of view, so that there is something it is like to be that body.

Although the explanatory gap does not go away when we adopt this perspective based on life or living being, it does take on a different character. The guiding issue is no longer the contrived one of whether a subjectivist concept of consciousness can be derived from an objectivist concept of the body. Rather, the guiding issue is to understand the emergence of living subjectivity from living being, where living being is understood as already possessed of an interiority that escapes the objectivist picture of nature, and living subjectivity is understood as already possessed of an exteriority that escapes the internalist picture of consciousness.

\section{Overview}

Mind in Life addresses this guiding issue in three stages.

Part One revises and restates the 'enactive approach' in cognitive science, first proposed by Varela, Thompson and Rosch (1991), and it links this approach to certain key ideas of phenomenological philosophy. In particular, I propose that intentionality can be related to the behaviour of autonomous self-organizing systems (pp. 27, 159), and that the notion of emergent dynamic patterns in autonomous systems provides a bridge to Merleau-Ponty's idea that certain forms or structures of behaviour are constitutive of life and mind (Chapter Four). 
Part Two offers an account of what it is to be a living being or living system; this account is based on integrating the theory of autopoiesis (Maturana and Varela, 1980; 1987) with the phenomenological account of life developed by Hans Jonas (1966). One of the key proposals of Part Two is that the theory of autopoiesis provides a naturalistic account of minimal selfhood and minimal cognition. Along the way I show how the theory of autopoiesis addresses Kant's concern to understand the organism as a self-organizing being by providing a naturalistic account of his conception of the organism as a 'natural purpose' (in a way Kant thought was impossible). Finally, by combining the theory of autopoiesis and developmental systems theory, I criticize genocentrism and adaptationism in evolutionary theory and in their place offer an enactive account of evolution and development.

Part Three focuses on consciousness. Here my concern is to bring the resources of phenomenology directly to bear on current topics in the cognitive and brain sciences and the philosophy of mind, specifically bodily awareness and self-consciousness (Chapter Nine), perception and mental imagery (Chapter Ten), time consciousness and temporality (Chapter Eleven), affect and emotion (Chapter Twelve), and empathy, social cognition and intersubjectivity (Chapter Thirteen). Throughout these chapters I give special attention to what phenomenologists call pre-reflective self-awareness (or pre-reflective self-consciousness), that is, the implicit and intransitive (non-objectdirected) ways we experience ourselves in world-directed cognition and action.

The relation between selfhood as a mode of being or structure of existence and phenomenal selfhood as a structure of experience stands at the heart of the body-body problem. This relation is precisely the relation between the living body (or living being) and the lived body (pre-reflective self-awareness as pre-reflective body awareness). Again, I do not propose to close this gap in Mind in Life or to bridge it in some speculative metaphysical way. Rather, my aim throughout is to develop new ways for science and philosophy to address this gap based on an appreciation of the deep continuity of life and mind.

\section{The Enactive Approach}

The term the enactive approach and the associated concept of enaction were introduced by Varela, Thompson and Rosch (1991) in order to unify under one heading several related ideas. The first idea is that living beings are autonomous agents that actively generate and maintain themselves, and thereby also enact or bring forth their own 
cognitive domains. The second idea is that the nervous system is an autonomous dynamic system: it actively generates and maintains its own coherent and meaningful patterns of activity, according to its operation as a circular and re-entrant network of interacting neurons. The nervous system does not process information in the computationalist sense, but creates meaning. The third idea is that cognition is the exercise of skilful know-how in situated and embodied action. Cognitive structures and processes emerge from recurrent sensorimotor patterns of perception and action. Sensorimotor coupling between organism and environment modulates, but does not determine, the formation of endogenous, dynamic patterns of neural activity, which in turn inform sensorimotor coupling. The fourth idea is that a cognitive being's world is not a pre-specified, external realm, represented internally by its brain, but a relational domain enacted or brought forth by that being's autonomous agency and mode of coupling with the environment. The fifth idea is that experience is not an epiphenomenal side issue, but central to any understanding of the mind, and needs to be investigated in a careful phenomenological manner. For this reason, the enactive approach maintains that the cognitive and brain sciences and phenomenological investigations of human experience need to be pursued in a complementary and mutually informing way.

There is also a deeper convergence of the enactive approach and phenomenology. Both share a view of the mind as having to 'constitute' its objects. 'Constitution' does not mean fabrication or creation; the mind does not fabricate the world. 'To constitute', in the technical phenomenological sense, means to bring to awareness, to present, or to disclose. The mind brings things to awareness; it discloses and presents the world. Stated in a classical phenomenological way, the idea is that objects are disclosed or made available to experience in the ways they are thanks to the intentional activities of consciousness. Things show up, as it were, having the features they do, because of how they are disclosed and brought to awareness by the intentional activities of our minds. Such constitution is not apparent to us in everyday life, but requires systematic analysis to disclose. Consider our experience of time (Chapter Eleven). Our sense of the present moment as both simultaneously opening into the immediate future and slipping away into the immediate past depends on the formal structure of our consciousness of time. The present moment manifests as a zone or span of actuality, instead of an instantaneous flash, thanks to the way our consciousness is structured. As I discuss (Chapter Eleven), the present moment also manifests this way because of the nonlinear dynamics of brain activity. Weaving together these two 
types of analysis, the phenomenological and neurobiological, in order to bridge the gap between subjective experience and biology, defines the aim of 'neurophenomenology' (Varela, 1996), an offshoot of the enactive approach presented in Chapters Ten and Eleven.

The enactive approach and phenomenology also meet on the common ground of life or living being. For the enactive approach, autonomy is a fundamental characteristic of biological life, and there is a deep continuity of life and mind. For phenomenology, intentionality is a fundamental characteristic of the lived body. The enactive approach and phenomenology thus converge on the proposition that subjectivity and consciousness have to be explicated in relation to the autonomy and intentionality of life, in a full sense of 'life' that encompasses the organism (Chapters Five and Six), one's subjectively lived body (Chapters Nine through Twelve), and the life-world (Chapter Thirteen).

\section{Conclusion}

One of the guiding ideas of Mind in Life is that the human mind is embodied in our entire organism and in the world. Our mental lives involve three permanent and intertwined modes of bodily activity self-regulation, sensorimotor coupling, and intersubjective interaction (Thompson and Varela, 2001). Self-regulation is essential to being alive and sentient. It is evident in emotion and feeling, and in conditions such as being awake or asleep, alert or fatigued, hungry or satiated. Sensorimotor coupling with the world is expressed in perception, emotion, and action. Intersubjective interaction is the cognition and affectively-charged experience of self and other. The human brain is crucial for these three modes of activity, but it is also reciprocally shaped and structured by them at multiple levels throughout the lifespan. If each individual human mind emerges from these extended modes of activity, if it is accordingly embodied and embedded in them as a 'dynamic singularity' - a knot or tangle of recurrent and reentrant processes centred on the organism (Hurley, 1998) - then the 'astonishing hypothesis' of neuroreductionism - that you are 'nothing but a pack of neurons' (Crick, 1994, p. 2) or that 'you are your synapses' (Le Doux, 2002) - is both a category error and biologically unsound. On the contrary, you are a living bodily subject of experience and an intersubjective mental being.

In this Précis I have chosen to highlight some of the book's main themes instead of summarizing the book's detailed analyses and arguments. My hope is that I have provoked the interest of my readers while orienting them to the commentaries and my replies. 


\section{References}

Chalmers, D.J. (1996) The Conscious Mind: In Search of a Fundamental Theory, New York: Oxford University Press.

Crick, F. (1994) The Astonishing Hypothesis: The Scientific Search for the Soul, New York: Scribners.

Hurley, S.L. (1998) Consciousness in Action, Cambridge, MA: Harvard University Press.

Husserl, E. (1997) Thing and Space: Lectures of 1907, Rojcewicz, R. (trans.), Dordrecht: Kluwer Academic Publishers.

Jonas, H. (1966) The Phenomenon of Life: Toward a Philosophical Biology, Chicago, IL: University of Chicago Press.

Le Doux, J. (2002) Synaptic Self: How Our Brains Become Who We Are, London: Penguin Books.

Maturana, H.R. \& Varela, F.J. (1980) Autopoiesis and Cognition: The Realization of the Living, Boston Studies in the Philosophy of Science, vol. 42, Dordrecht: D. Reidel.

Maturana, H.R. \& Varela, F.J. (1987) The Tree of Knowledge: The Biological Roots of Human Understanding, Boston, MA: Shambala Press/New Science Library.

Merleau-Ponty, M. (1942/1963) The Structure of Behavior, Fisher, A. (trans.), Pittsburgh, PA: Dusquene University Press.

Thompson, E. \& Varela, F.J. (2001) Radical embodiment: Neural dynamics and consciousness, Trends in Cognitive Sciences, 5, pp. 418-425.

Varela, F.J. (1996) Neurophenomenology: A methodological remedy for the hard problem, Journal of Consciousness Studies, 3 (4), pp. 330-350.

Varela, F.J., Thompson, E. \& Rosch, E. (1991) The Embodied Mind: Cognitive Science and Human Experience, Cambridge, MA: MIT Press. 